\title{
Threats and Linkages of Regional Integration. A case of SADC Member States
}

\author{
Langton Mutoya \\ Africa University of Zimbabwe College of Peace, Leadership and Governance \\ DOI: 10.29322/IJSRP.10.11.2020.p10771 \\ http://dx.doi.org/10.29322/IJSRP.10.11.2020.p10771
}

\begin{abstract}
Regional communities have proven over the years to play an important role in sustainable development and transformation worldwide. African nation states remain committed to implementing its regional integration agenda through its eight established Regional Economic Communities (RECs) within the continent. Although some significant progress has been recorded to date, the multiplicity of inter-governmental organisations and diversity of business setups in Africa and overlapping memberships in the RECs poses some threats. Notably, threat of disconnection between governments and private sector. Contrary, there is potential linkages for Regional Integration (RI) that foster implementation of regional agreements at a larger scale. It is widely acknowledged across the globe that Africa's integration efforts have unsatisfactorily provided desirable results in comparison to other continents such as Europe and Asia. This paper explored threats and potential linkages embodied in regional integration and the nationalistic concerns from the generation ranging from the Africa founding fathers of neo-colonialism to the current $20^{\text {th }}$ century states leadership ideologies focusing on the case study of Southern African Development Community (SADC). The research was a qualitative case study of the sixteen SADC member states and is informed by secondary data. The author reviewed the current twenty-six SADC protocols, website and google scholar to explore the SADC guiding processes, economic profile, demographic dividend and philosophy.
\end{abstract}

Index Terms- Regional Integration, SADC Protocols, Regional Economic Communities, SADC

\section{INTRODUCTION}

$\mathrm{R}$ egional integration suffices when a group of countries get together and develop a formal agreement. In most cases, this is by way of treaties regarding how they will conduct their regional relationships with each other. Regional integration in this study therefore denotes a phenomenon where a group of countries occupying a particular close geographical area for the safeguarding or promotion of members, and operate on terms that are fixed by treaties, or other rules and regulations. Regional integration globally is viewed as an important mechanism to boost the economic growth of most neighbouring states (Cheru, 2002). The difference of regional integration from a global perspective is originated from factors such as increased trade opportunities, desirable foreign direct investments (FDI), demographic dividend, bilateral and multilateral arrangements, improved regional relationships, and sustainable infrastructure (De Melo \&Tsikata, 2014). As a result of this, (Masemola, (2005) proclaims that, from an African viewpoint, regional integration was observed as a way of redressing Africa's underdevelopment, colonial legacy, and dependence on first world nations.

Africa's regional integration can be traced as far back as the development of the Organisation of African Unity in 1963, which saw thirty-six Africa member states coming together with the intention of achieving greater unity and peace within the region. This inter-regional organisation was leveraged on the realisation that in order to achieve any economic growth or peace on the African Continent, member states would have to work together. Continental and inter-regional cooperation and integration efforts have been ongoing for several decades now.

The Southern Africa regional economic initiative is called Southern African Development Community (SADC). Southern African Development Community (SADC) is the predecessor of the Southern African Development Coordination Conference (SADCC), established in 1980 in Lusaka, Zambia. The community now consist of a sixteen member states. These are, Angola, Botswana, Democratic Republic of Congo, Comoros, Lesotho, Madagascar, Malawi, Mauritius, Mozambique, Namibia, Seychelles, South Africa, Swaziland (eSwatini), Tanzania, Zambia and Zimbabwe

Regional integration theory proved that such cooperation can positively contribute to capacity development, infrastructure and economic development across countries and regions (Schimmelfennig, 2018).

Broadly, the success to Africa integration has been tied to the continental economic initiatives and political decisions. The Abuja Treaty stipulated that African States must work to strengthen their regional economic communities, in particular by coordinating, harmonizing and increasingly integrating their activities in order to attain the African Economic Community (Abuja Treaty Minutes, 2000). To measure the process of integration, the Observatory on Regional Integration in Africa has identified five key pillars derived from treaties and protocols of the African Union and the Regional Economic Communities (RECs). These pillars are namely: - trade and market integration, macroeconomic policy convergence, free movement of persons, peace, security, stability and governance and harmonization of sectoral policies.

When SADCC started, its vision was mainly to become a coordination alliance and its main purpose was to coordinate development projects in order to lessen the economic hardships and dependence on the then apartheid South Africa. Since its 
establishment as SADCC in 1980, SADC has gone through a number of transformations encountering challenges and opportunities mainly; the transformation processes from a Coordination Conference into a development Community (1992); expansion in areas of cooperation and integration and in its development projects; increase in membership (from nine in 1980 to the current sixteen ); restructuring of institutions, that is, moving from member states coordinated programmes to a centralized structure based at the secretariat; challenges and opportunities deriving from the New Partnership for African Development (NEPAD), the Globalization Process, Poverty, and HIV and AIDS and other communicable diseases.

In 1992, as all the member states where liberated SADCC saw it important to change the name to SADC and it aligned the bloc more to a legal entity and refocused its development agenda towards economic integration. SADC became an inter government organisation with ambitions of a sound regional integration, social and economic cooperation The new focus was inclined to driving regional integration in economic, social and security cooperation in the region. Then SADC pronounced its new mission as to ensure promotion of equitable development and sustainable growth that enhances economic, political, peace and stability in the region. The establishment of an African peace and security mechanism has become a common topic of discourse in political, security, and academic circles. The organisation of SADC is mainly in two facets that can be explained as legal entity and region which is expected to drive the economic benefits to the citizens. Basically, SADC as regional body was meant to increase the development of regional policies that are expected to strengthen socio-economic development for the region. Since inception, SADC has enacted many policies which aim at encouraging regional growth (Mapuva, J. \& Muyengwa-Mapuva, L, 2014).

Within the continent, some of the other strongly related regional economic communities include the continental body called African Union (AU) and New Partnership for African Development (NePAD). Together, the three key regional and continental institutions has a strong working relationship. According to the SADC Regional Strategic Indicative Development Plan, NePAD, AU and SADC are strongly collaborative. African Union initiated NePAD, and as such is an implementation tool for the overall goals of the African Union. On the other hand, the goals and mandates of SADC are closely linked to the mandate of NePAD. Recognising these linkages, the SADC Ministers of Foreign Affairs and Finance Meeting in September 2001 concluded that SADC should be considered a part of NePAD. The rationale was suggested that, NePAD is a framework and plan of the African Union, while SADC is a recognised regional economic community of the same Union. As such, the strengthening and continued success of the implementation of projects within SADC enhances the success of the broader NePAD framework. Broadly, SADC participates in NePAD and the AU. The Ministers recognised that NePAD is a framework and process within the Union, while SADC is a recognised REC of AU. SADC participates, therefore, in both the Union and NePAD. This study examined SADC. Emphasis is on the trade and market integration which apparently is an AU pillar of regional integration. This study aims to exam the existing threats and current potential linkages embodied in this regional integration.

\section{StAtement OF THE PRoblem}

A number of targets that the SADC regional bloc has set to attain since inception in 1992 have not been achieved. According to SADC Protocol on Trade Article 3 there is growing frustration being evident among SADC leaders who have increasingly demonstrated distrust towards the attainment of the intra-trade and market integration in the region. SADC liberalisation of intraregional trade as well as establishing of a common regional market as targeted since inception were not achieved. In the SADC Trade Protocol signed by eleven out of the fifteen member states in 2000 , the countries sought to liberalise $85 \%$ of intra-regional trade by 2008 , liberalise $100 \%$ of trade by 2012 , and form a customs union for the region by 2010. All these targets have since been missed. In addition, the region has set itself to establish a common market by 2012 and a monetary union by 2016, both of which have not been achieved. The study inquired the existing threats and linkages for SADC regional integration that contributed to these elaborated failures.

\section{Methodology}

The study was cross sectional and reviewed records on treats and linkages affecting SADC as a regional bloc. This assisted in the examination of the threats and linkages within the SADC regional integration. Focus was on the trade and market protocol. SADC website and google scholar were used to examine the SADC agreements, economic profile, potential demographic dividend and sovereignty syndrome. The collected literature was used to explore the existence of threats and potential linkages embodied in regional integration against the nationalistic concerns from the generation ranging from the Africa founding fathers of neo-colonialism. Descriptive and qualitative analysis was employed on this secondary data to have an understanding of the concept of regional integration in the context of Southern Africa. The rationale of this approach was to put into context the understanding of the underlying concept of regional integration in Southern Africa and answer the study questions. The sixteen SADC member states were the targeted population. The analysis was guided by the study research questions.

\section{RESEARCH QUESTIONS}

i. Why SADC regional integration is not as successful in comparison to the other regional blocs such as the Asia and European Union?

ii. Are there threats and market linkages within the Southern Africa region?

iii. Are the existing trade and market opportunities being utilised individually or as a bloc?

\section{Hypothesis}

Ho: There are no threats and linkages for regional integration within SADC bloc. 


\section{OBJectives}

i. To examine why SADC regional integration is not as successful in comparison to the other regional blocs such as the Asia and European Union

ii. To assess the threats and market linkages within the Southern Africa region

iii. To examine if the existing trade and market opportunities are being utilised individually or as a bloc

\section{Conceptual Framework}

The study conceptualised that threats and linkages for Regional Integration cannot be measured only by looking at geographical proximity. To measure the process of integration within SADC region, the study identified five key pillars derived from treaties and protocols of the African Union and the regional economic communities:

- Trade and Market Integration

- Macroeconomic Policy Convergence

- Free Movement of People Structural

- Harmonized Policies

- Political Governance, Peace, Security and Stability

Source: Observatory on Regional Integration in Africa

\section{History of Regional Integration in Africa}

African member states all belong to the collective security arrangement construed from the United Nations (UN) charter. On the other hand, African countries also belong to their stand-alone continental organisation called African Union (AU) formerly OAU which since the Cairo declaration of 1993 is regarded as a regional collective security arrangement guided by the chapter viii of the UN charter. A number of geographically proximate Africa states further affiliate to regional collective defence agreements such as the treaty of Non-Aggression, Assistance and Mutual Defence; known by its French acronym - ANAD.

In Europe, although often misperceived as a regional organization, NATO is a multinational alliance for collective selfdefence, as was the War-Saw Pact. A defensive alliance, according to art of the UN charter, may use force in self-defence without waiting for the Security Council (SC) to take action, (only in response to an armed attack). Contrary, Article 53 (1) of UN charter allows a regional organization to take enforcement action even if there was no prior armed attack, but with the SC authorization. Article 54 further proclaimed that, the SC shall at all times be appraised of regional agreements for the maintenance of international peace and security.

At its 37th Ordinary Session in Lusaka, in July 2001, the OAU Assembly of Heads of State and Government adopted what they called African initiative. The initiative was named the New Partnership for Africa's Development (NePAD). NePAD sought to examine the preparedness of the Africa continent's political and economic institutions against the forces of globalization. In other words, NePAD visualized a partnership with the North and various multilateral and multinational institutions.
AU desired to promote the tabled democratic principles to foster peace, security and stability, unity and solidarity between African countries and African peoples. The reasoning was to advance the African led political and socio-economic integration. In a way, AU acknowledged partitioning of Africa into five main sub-regions and prioritized a corresponding organization for each area. The recognised five regions are:- the Inter-Governmental Authority on Development (IGAD) in the east, the Economic Community of West African States (ECOWAS) in the West, the Arab Maghreb Union (known by its French acronym - UMA) in the North, the South Africa Development Community (SADC) in the South, and the Economic Community of Central African States (ECCAS) in the Central Africa sub-region. ECOWAS appears to be the best known of these organizations, having gained a good measure of international recognition through its massive peacekeeping efforts in Liberia and Sierra Leone. SADC region which is the impetus of this study gained a reputation for involvement in conflict resolutions activities and IGAD assumed the similar role in the resolution of sub-regional conflict. The existence of these sub-regional integration organizations, in itself, are argued as constituting threats to regional trade and economic linkages.

In many integration attempts in these African sub regions, political leaderships have resentfully protected their sovereignty and therefore not willing to compromise any of it to supranational powers. As a result, national political agents tended to detect the pace of the nature of participation in the integration initiatives. The transfer of some powers was envisioned as providing sub-regional secretariats with the necessary legitimacy. In summary, the nucleus of political will in Africa constituted an important test of commitment to an integration project. This means that strong institutions at sub-regional level would be indispensable for implementing this increasingly diverse policy and project initiatives for integration arrangements.

\section{Lessons from ASEAN for Regional Integration in Africa}

The Association of South and East Asian Nations (ASEAN) is more than 50 years old. It was formed 1967, in Bangkok, Thailand. The founding members were Indonesia, Malaysia, the Philippines, Singapore, and Thailand. Over time, it grew to include Brunei Darussalam in 1984, Vietnam in 1995, Laos and Myanmar in 1997, and Cambodia in 1999. Today, these countries form the 10 member states of ASEAN.

In 1937, long before the region became the economic success story we admire today, Kaname Akamatsu, a Japanese scholar, developed the Flying Geese paradigm theorizing on how technological development could be promoted in Southeast Asia from Japan as a leading regional anchor. Kiyoshi Kojima, a proponent of the paradigm, argued in the 1970s that in the presence of scale economies, countries could gain from specialization even when they had similar technological levels and factor endowments. He developed a simple model in which two identical countries could produce two goods under conditions of perfect competition and identical external economies of scale. Welfare would be higher if the countries integrate and each specializes in one of the goods instead of producing both. Kojima proposed that regional agreements could help facilitate technology transfers and productivity growth following the Flying Geese paradigm. Trade integration would in turn further strengthen 
cooperation as it reduces rivalry in product markets, setting in train a virtuous cycle.

Japanese theorists also conceptualized the linkages among various overseas activities of Japanese transnational corporations through subcontracting, licensing arrangement, joint ventures, and foreign direct investment with the theme of regional integration in East Asia. Their ideas helped both policymakers and the private sector map out an implementable regional integration plan. They foresaw that packaged real and financial asset flows from Japan to follower economies would augment the benefit of inter-economy linkages-both for Japan and for ASEAN countries. Foreign direct investment, which began to grow in the 1970s and dramatically accelerated after the mid-1980s, facilitated Japan's economic restructuring - scaling down industrial sectors that were losing competitiveness and releasing resources for the sectors gaining competitiveness-while simultaneously aiding the structural transformation of many ASEAN countries.

The second thing Africa can learn from the private-sectorled regional integration in ASEAN is about the central role of family businesses. Large, diversified, family-owned businesses are indeed dominant players in ASEAN+3 (the ASEAN 10 plus China, Japan, and Korea). The family is the basic unit of management, making possible speedy decisions, and providing loyalty, flexibility, and low overheads. It also breeds trust, a crucial business element in all circumstances but especially in settings where governance is weak. Ronald Coase's conceptualization of the nature of the firm-coincidently published in 1937 - as an arrangement to reduce organizational costs is consistent with this view.

When Henry Sy, the most successful Chinese entrepreneur in the Philippines, invited his children and grandchildren for Sunday lunch, six of his company executives would show up, allowing for a discussion of plans and finances in a convivial and confidential family gathering. The Charoen Pokphand (CP) Group, Thailand's largest conglomerate whose wealth is estimated at more than $\$ 5$ billion, began as a small farm-seed company founded by a Chinese merchant who had moved to Bangkok. The company grew into a conglomerate as it expanded the market for its seed. CP now controls more than 200 companies in Thailand, Indonesia, Taiwan, Turkey, Portugal, and the Philippines. Many Western companies that later moved successfully into mainland China - such as Motorola, Coca-Cola, KFC, Lockheed, Chrysler, and Procter \& Gamble-have done so by forming joint ventures with members of Chinese family conglomerates.

To be sure, such arrangements can have drawbacks. The industrial titans of the Gilded Age in the United States were largely family businesses, and the economy they built was one of the most unequal in recent times. Today, in most developed nations, the largest industry-leading companies are typically held by a broad, dispersed mix of shareholders; e.g., fewer than a third of the companies in the S\&P 500 remain founder- and family-owned businesses. But as brisk growth propels emerging economies forward, a 2014 McKinsey article suggests that by 2025, family conglomerates will represent nearly 40 percent of the world's large enterprises, up from roughly 15 percent in 2010 (Figure 1). Southeast Asia will be leading the pack; Africa will be bringing up the rear. This is something about which Africa's leaders should think, and African economists theorize.

\section{SADC Historical Transformation to Regional Integration}

The focus of SADC from inception was on addressing the causes of colonial political liberation in Southern Africa, and reduction of dependence on the apartheid South Africa. Resolutions were passed that, the regional organisation coordinate and leverage on the strengths and resources endowment of each other. Therefore, SADCC was formed with four principal objectives, namely: reduction of member state dependence, particularly, but not only, on apartheid South Africa; building of linkages to create sincere and unbiased regional integration; mobilisation of member states' resources to promote the implementation of national, interstate and regional policies; and concerted action to secure international cooperation within the framework of the strategy for economic liberation.

In 1992, Heads of Government of the region agreed to transform SADCC into the Southern African Development Community (SADC) inclining the focus to integration for regional economic development. From inception, SADC developed the desire to establish a regional integration, regional economic linkages, strengthening of the region's economic performance, and enhancement of the region's political stability.

The predominant objective of the SADC over the years has been to promote economic and social development through cooperation and economic integration. SADC transformed to attainment of regional economic integration, freedom and social justice. The transformation was anchored in the sharing of common values and principles that exist between the populations of Southern Africa. As a result, this transformation put SADC's mission as promoting sustainable and equitable economic growth and socio-economic development; deeper co-operation and integration; as well as good governance and durable peace. Regional integration was identified as a vehicle of which this vision would be attained. The member states projected building economic linkages as the mode of harmonising the regional integration benefits. In addition to desire of economic linkages, the SADC mobilised for resources to promote the implementation of national, interstate and regional policies. The bloc further committed to collaborate to secure a stronger international bargaining power. However, the quest by the SADC regional bloc to achieve these objectives has resulted in programmes and linkages being put in place.

Since inception, regional integration has increasingly been elusive regardless the fact that SADC has presented opportunities for different countries to harmonise the member states' different needs. SADC member states seem not pulling together towards the same goal of regional integration as evidenced by the continued existence of concurrent memberships. To date, SADC has not yet achieved its projections of liberalisation of intra-regional trade as well as establishing a common market as was targeted during its inception. Statistics show that SADC intra-regional trade is still on average 10 percent which is lower than optimum. Against a target of $85 \%$. Against intra-regional trade of other regions such as Asia and Europe, the percentage is also comparatively lower. On average, intra-regional trade in Asia is 24 percent and in European Union 40 percent (Chidede, 2017). These statistics provide evidence that, there is still existence of different trade and market preferences contrary to the fact that SADC as a treaty envisaged equality and unity of purpose among member states. 
Integration in SADC in terms of linkages realized and challenges encountered, reveals that implementation has progressed well despite the several challenges documented. SADC has been successful across a wide range of areas relating to regional cooperation and integration in comparison to other continental regional blocs. Despite the noted differences across the SADC member states, the most important achievement towards regional integration is that, appropriate policy frameworks, protocols and decisions, ratified and domesticated within the key pillars identified were put in place.

In the process of implementing the various initiatives within the SADC bloc regional integration, linkages are drawn from the challenges of domestication of agreed policies and legal frameworks, roadmaps for implementation, enforcement and follow-up mechanisms, administrative issues, capacity issues, statistics and information sharing, and budgetary constraints. This study examine the linkages and challenges posed under regional integration in SADC and sought to inform SADC member states and the wider range of relevant stakeholders on the progress made in achieving the regional integration agenda. The examination focused on the four key pillars namely: - industrial development and market Integration; infrastructure development in support of regional integration, special programmes of regional dimension; and peace and security cooperation to guide on answering the research questions.

\section{Trade and Market Integration}

At Africa continental level, there is documented efforts to scale up the intra-African trade. A number of policy frameworks were developed to stimulate the trade of goods and services through regional integration agreements designed to eliminate tariff and non-tariff barriers. Although a number of trade and market integration-related agreements, protocols and conventions have been signed among member states in their respective regional economic communities, a number of factors have contributed to its slow implementation. Among the main barriers to trade, are poor infrastructure developments, maintenance and connectivity, and conflicts and security issues in sub regions.

Moreover, a number of the continent's railways and roads often lead to marine ports rather than cross-border linkages over land. Internal waterways are, similarly, insufficiently exploited and in most cases underdeveloped, making it difficult to conduct intra-continental business. Further emphasis to revamp national transport and infrastructure that can create linkages among African regions is therefore needed in order to improve the movement of goods and services across the continent. Regional infrastructure development programmes, such as the Programme for Infrastructure Development in Africa, are thus optimum ways to achieve continental connectivity for Africa. It is equally imperative that African countries and regional economic communities streamline and apply existing regional trade agreements into their national policy and executive bodies to obtain the benefits associated with deeper trade and market integration in Africa.

The rationale of pursuing trade and market integration within the SADC bloc is to increase intra-African trade and investments. The assumption of this researcher is, when trade relationships are existent and cost-effective, business and consumers in the regions benefit through creation of employment opportunities, foster industrial linkages, improve economic diversification and structural transformation that, by extension, generate sustainable development in the region. Intra- SADC trade remains lower than optimal. Enhancing intra-African trade, therefore, has the potential to contribute to further specialization, diversification and structural transformation within the region.

\section{Macroeconomic Policy Convergence}

Theoretically, macroeconomic policy convergence, financial and monetary integration are key variables in enhancing efficiency, promoting public accountability and economic growth. Macroeconomic policy convergence if set appropriately contributes to reductions in economic fluctuations. Harmonisation of regional macroeconomic policies contributes to economic stability within an identifies region.

Proficient macroeconomic policy convergence supports successful cross-border financial and monetary integration that stimulates trade among countries. The benefits of financial and monetary integration are dependent on the extent of trade among countries and the feasible trade creation on the continent. In the context of SADC regional integration, monetary integration is consistent to the sixth phase of the Abuja Treaty (a single currency by 2028, including an African Monetary Union and a Pan-African Parliament), initiatives of customs and monetary unions. SADC moved its motion on monetary union but to date the motive is not yet being exercised by the member states. The free movement of people across borders have been high on the regional integration agenda for member States, primarily because of the prospective trade gains that are associated with it.

\section{Free Movement of People}

Free movement of people across SADC represents a powerful instrument to economic growth and skills development when people can travel with ease for business, tourism or education. Synergic benefits accrue to member states that opens up their as seen in the growth in remittances in past years. Currently, it is not a prerequisite that member states implement the free movement of people principle.

It is fundamental to note that the free movement of people and the rights of residence and establishment constitute the fifth phase of the Abuja Treaty that is projected to be realized by 2023. Progress to date indicate that the regional businesses are not able to attain, move or retain professionals because of restrictive immigration laws that impede the mobility. Getting visas within the African continent and its sub regions has been a critical constraint to success of regional integration. Efforts were made to tackle the constraint at continental level through the African Union advocacy. The African Union advocate for the "single African passport" that aims to fulfil the above objective and improve intraAfrican trade as a part of Agenda 2063.

\section{Harmonized Policies}

Harmonized policies generate common understanding and team work. Common policies allow for economies of scale that lay a foundation for sustainable economic development and regional integration. It is, therefore, a core objective of the Abuja Treaty and Agenda 2063 for policies and regulations to be harmonized in all areas of the economic sphere including the sub regions such as SADC. The Abuja Treaty (1991) states that, 
strengthening of sectoral integration at the regional and continental levels in all areas of activity particularly in the fields of trade, agriculture, money and finance, transport and communications, industry and energy; and co-ordination and harmonisation of activities among the existing and future economic communities.

In this context, the minimum threshold for sectoral policy integration of member states in regional economic communities was supposed to have been met in 2007 to achieve the stated Africa objectives. SADC is a sub-region of AU therefore the same target applied to its member states. According to this researcher, SADC harmonized policies, regulations, procedures and monitoring mechanisms in practice are questionable despite the fact that, member states individually and collectively have a responsibility to superintend that harmonization of sectoral are implemented. The examination of the harmonized policies provided a platform to test the existing threats and linkages for SADC considering the pillar of regional integration.

\section{Political Governance, Peace, Security and Stability}

Political governance, peace, security, and stability are key tenents to achieving functional regional integration. Consideration of low Gross Domestic Products (DGP) per capita states, and unstable governance (mainly due to persistent ethnic disputes) have been stallers of regional integration progress. Historically, regional integration has been a driver for reduction of armed and non-armed conflicts and the driver of regional stability in many regions across the world. It is, however, the regional integration mechanisms that foster security within the African Union member states. These mechanisms within the regional economic communities SADC included have the obligation for promoting peace, security and stability in the continent of Africa at large. As such, SADC regional integration established formal institutional frameworks and developed peacekeeping mechanisms in their respective communities. The examination of the political governance, peace, security, and stability provided this study an opportunity to test the existing threats and linkages for SADC considering the pillar of regional integration.

\section{FINDINGS AND DISCUSSION}

Why SADC regional integration is not as successful in comparison to the other regional blocs such as the Asia and European Union?

The study found the following factors as reasons why SADC regional integration is not a success story in comparison with other regional unions. The factors were identified as a combination of socio-economic and geo-political whose continued existence keep on hindering the successful consolidation of regional integration in the region.

\section{Economic growth and development:}

SADC member states are reluctant to implement policies aimed at harmonizing trade policies, labour movement, investment policies and regional (Oosthuizen, 2006). Reluctance on agreed policies aimed at increasing integration was found as an impediment factor in economic growth and development within the SADC region. Furthermore, SADC member states have not prioritized the implementation of economically friendly policies that would induce growth and development. Faye et al. (2004) however, mention that many countries in Southern Africa are confronted many internal challenges; hence many countries are focusing in fighting internal challenges rather than focusing on policies meant to consolidate regional integration further. Generally, there is a disconnection between governments and private sector.

\section{Infrastructure challenges}

Lack of enabling environment and appropriate infrastructural development initiatives in Southern Africa hinders progress towards regional trade, affects the growth potential of regional economies and ultimately the regions ability to attract foreign direct investments (Huang, 2010). Poor infrastructure characterizes the SADC region. This contributes to a low rate of industrialization and poor rates of economic growth. Subsequently, infrastructure investment becomes very difficult (Khandelwal, 2004). Ideally, the provision of free trade and the liberalization of trade policies require reliable and functional infrastructure for them to be fully entrenched and beneficial for member states.

\section{Late ratifying of protocols:}

SADC has not prioritized the realistic realignment and ratification of regional trade policies. This has created a hindrance to the aim the SADC which is to promote regional integration and growth (Crush \& Dodson, 2017). The late implementation of agreed policies is attributable to mistrust or unwillingness among member states (Aall \& Crocker, 2017). For example, the free labour movement policy has not been ratified despite the continuous call by the SADC member states to implement such a policy.

\section{Poverty, Epidemics and Persistent droughts:}

SADC failure to implement economic policies that promote growth has worsened the poverty and HIV problem (Tekere, 2012). The region is characterized by a high number of people living in poverty and this has affected the ability of regional member states to prioritize regionalism as they have had to divert resources in order to combat the increasing rate of poverty in the region (Zungu-Dirwayi, 2004). The ever-increasing rates of HIV infections in the region pose a significant challenge. HIV decrease the availability of skilled human capital and this will further hamper regional integration efforts. Most economies of the member states are strongly agro-based. Persistent droughts in the region affected agro-products production. Poverty, HIV and poor agriculture produce increased the rate of under development in the region and in the end increased the failure to consolidate regional integration in Southern Africa fully.

\section{Are there threats and market linkages within the Southern Africa region?}

The study found the following threats as key factors that are impeding successful regional integration efforts by member states to integrate and increase cooperation within SADC region. Generally, these threats are administrative and political in nature. The potential linkages were also identified and discussed.

\section{Multiple and overlapping memberships}


Multiple and overlapping memberships of SADC member states have been a notable threat to economic regional integration within the region. Majority of the SADC member states are also members of the COMESA. South Africa, Botswana, Lesotho and Swaziland are members of both the SACU and the SADC, while Namibia and Swaziland both hold memberships of three regional integration agreement (including the COMESA) and are part of the Common Monetary Area (which include South Africa and Lesotho) and also participate in the Regional Integration Facilitation Forum (RIFF). Overlapping membership of different RECs has not only created confusion, competition and duplication, but also constitutes a burden on the taxpayer. Moreso, this causes problems in the with regards to decisions to form a customs union. The customs union principle is that; no one country can simultaneously belong to two RECs at any given time.

The study also noted that, within the SADC region, there are differences in means to integration due to observed inconsistency and disjointedness in member states trade policies. Taking for example COMESA and SADC, COMESA view the benefits of integration as derived from the removal of trade and non-tariff barriers. Whereas, SADC view economic independence and political security as basis of sectoral co-operation.

Another observation is, failure by member states to commit and comply with the requirements of the SADC Treaty to regional integration. This has been associated SADC failure to coordinate and harmonise trade activities within the bloc. Existence of multiple integration unions and overlapping membership and the continuing negotiations with countries outside the SADC region was found to be a threat to the agreed scope of integration in the region.

The co-existence of the SADC and other unions within the region has created further challenges for the SADC bloc focus on achieving successful regional integration objective. This study noted that, SADC member states are divided between various other continental and global institutions which pursue the same objectives. Competing other powerful economic blocs, such as, the EU contribute to the weakening of SADC unison by directly negotiating with the member states instead of under the banner of SADC as a regional cooperative bloc. These forces were found as factors that threatened and derailed the SADC efforts for regional integration, especially given that the membership concur on agreed trade policies in meetings but in practice they applying different individualist interests.

\section{Development inequalities and diversities of economies}

SADC region is characterised by inequalities and imbalances of economies. The heterogeneity of SADC economies observed in this study has been identified as a major threat to the success of regional integration within the bloc. The diversity of these economies need serious committed member states to be integrated. There is disharmony within the regional bloc that, some member states with stronger economies than others are enjoying a comparative advantage against the weaker economies.

Historically, South Africa has been the dominant economic hub of the Southern Africa region. Findings of this study reveal that, South Africa's commitment to regional integration is questionable. mainly due to the fact that its economy has been able to attract trading partners outside of the SADC more than other SADC member states.
Hancock in his study, concurs with this argument by asserting that given that South Africa as a stand-alone state has realised more economic benefits than if it trades under both SACU and SADC membership. This suggests that its commitment to regional integration which does not offer more is compromised.

Gibb further argues that the variations in economies in the SADC has led to growing inequalities among member states. An example is the customs union theory which predicts that, member states with stronger economies receive more gains than others hence claims of inequalities. Findings of this study are in line to both Hancock and Gibb $h$ points of view on the impact of the heterogeneity of SADC economies on regional economic integration since regional integration would be difficult to achieve in such a state of inequality among member states.

There are notable different levels of economic development with the Southern Africa regional bloc. Variations in levels of economic development, nature of resources and political state within SADC membership found in this study further threaten the functionality of the regional bloc. In this regards, the Southern Africa regional body's major economic threat has been failure to create an enabling environment for the accomplishment of viable rates of equitable economic growth which, if it was achieved, would promote regional economic integration.

This study found that, most SADC member states are still experiencing low and decreasing levels of per capita Gross National Product, low growth rates of GDP, relatively high deficient and interest rates, and relatively low savings and investments rates. The economic developments of the SADC region have since inception increasingly become uneven. This inequality in this study is identified as a threat to regional economic integration.

\section{Potential Linkages}

The study found that, although the heterogeneity of Southern African states is a challenge to integration, the diversity of the economies provides an opportunity for linkages among member states. The diversity provides an opportunity to assess the different types of comparative advantage within the bloc. Linkages that come with opportunities created were found to potentially promote development amongst SADC member states. In addition, this researcher argues that, African Regional Trade Agreements (RTAs) are flexible legal regimes and as such, they provide opportunities for linkages through co-operation and integrated development of common resources, the equitable distribution of gains from trade, and the principle of variable geometry. Given that each member state economy is unique the identified overlapping membership has presented an opportunity for different countries to address their different needs Linkages and cooperation are seen as vibrant vehicles of attractive investments within the Southern Africa region.

\section{RECOMMENDATIONS}

The study recommends that, SADC region needs policies that are first tried and tested at the Southern Africa regional level. These policies are envisioned to promote political and economic reforms at the regional level and focus on continuing harmonization of policies and economic growth coordination. Furthermore, these policies are encouraged to take into account 
the diversity and economic capacity and geo-political dimensions of regional states (Qobo, 2007). By making efforts to overcome these regional barriers, the region will not only address some of the challenges currently prevalent but also promote some economic development in its regional integration endeavours both in the short and long run. The following are other summarised recommendations:

i. The study challenge SADC to prioritize regional integration with the aim of achieving sustainable growth and development;

ii. Public-Private-Partnership commitment to implement the Regional Indicative Strategic Development Plan (RISDP).

iii. Review and streamline the management structure of all SADC institutions. Harmonisation of the management and administrative procedures and rules, varying standards, qualifications and performance criteria for staff involved in the management of the regional programme.

iv. Provide mechanism that address deemed benefits within the disparity in, and inadequate provision of resources and staffing by member states leading to inequitable distribution of responsibilities and obligations.

v. Strengthen institutional mechanism for Ministers responsible for Foreign Affairs in the SADC region to discuss and coordinate common positions on matters pertaining to the organization at various international fora.

vi. Strengthen SADC institutions in order to make them effective avenues for the attainment of deeper integration that would in the long run deliver a stable and prosperous development Community.

\section{CONCLUSION}

Broadly, regional integration is about free movement of goods across the identified region. In this case the SADC region. This means getting goods to move more easily across borders; transport, energy and telecommunications to connect more people across more boundaries; people to move more freely across frontiers, and capital and production to move and grow beyond national limits. Regional integration is a development priority for Southern Africa. Integration matters in SADC and Africa as a continent. It affects what people can buy; the variety of what is on offer at the local market; how easily citizens move between countries; where individuals travel for leisure or for work; how cost-effective it is to keep in touch; where people choose to study or look for a job; how to transfer money to family or get start-up capital for a business. Based on the findings of this study, the researcher disagrees with the hypothesis that there are no threats and linkages for regional integration within SADC bloc.

\section{REFERENCES}

[1] Ahmed, AK "An analysis of the regional integration in Sothern Africa: A South African perspective" (2008) Tralac 12.

[2] Chingono M \& Nakana $S$ "The challenges of regional integration in Southern Africa" (2008) 10(3) African Journal of Political Science and International Relations 396-408.

[3] Draper P \& Kalaba M "South African international trade diplomacy: Implications for regional integration" (2006) at 37.

[4] Mapuva, J. \& Muyengwa-Mapuva, L. (2014). The SADC regional bloc: What challenges and prospects for regional integration? Law, Democracy and Development, 18, 22-36.

[5] Nyiraba M (2004). "Appraising Regional Integration in Southern Africa." Africa Security Review 13(1).

[6] Tekere, M. (2012). Regional trade integration, economic growth and poverty reduction in Southern Africa. African Books Collective. Cape Town

[7] Qobo M "Regional integration, trade and conflict in Sothern Africa' (2007) South African Institute for International Affairs 15

[8] Initiatives at the regional economic communities include the Protocol on Finance and Investment of the Southern African Development Community (SADC), the Investment Agreement for the COMESA Common Investment Area, the East African Community Model Investment Code and the Supplementary ACT A/SA.3/12/08 Adopting Community Rules on Investment and the Modality for their Implementation with ECOWAS.

[9] Economic Commission for Africa, Investment Policies and Bilateral Investment Treaties in Africa: Implication for Regional Integration, (Addis Ababa, 2016)

[10] Economic Commission for Africa, Linkages between Double Taxation Treaties and Bilateral Investment Treaties, (Addis Ababa, 2018)

[11] Economic Commission for Africa, Drivers for boosting intra-African FDI flows towards Africa's transformation, (Addis Ababa, 2018)

[12] Article 2, Protocol on Trade in the Southern African Development Community (SADC).

[13] Abuja Treaty Minutes, 2000).

[14] Africa Regional Integration Index, Report 2016

[15] Southern African Development Community Regional Indicative Strategic Development Plan

[16] ECA (Economic Commission on Africa) 2004. Assessing regional integration in Africa. ECA Policy Research Report. Addis Ababa: ECA.

[17] ECA 2005. Economic report on Africa 2005: meeting the challenges of unemployment and poverty in Africa. Addis Ababa: ECA.

[18] www.sadc.int (accessed 15/10/20)

\section{AUTHORS}

First Author - Langton Mutoya, Africa University of Zimbabwe College of Peace, Leadership and Governance . E-mail: mutoya2007@yahoo.com; mutoyal@africau.edu 